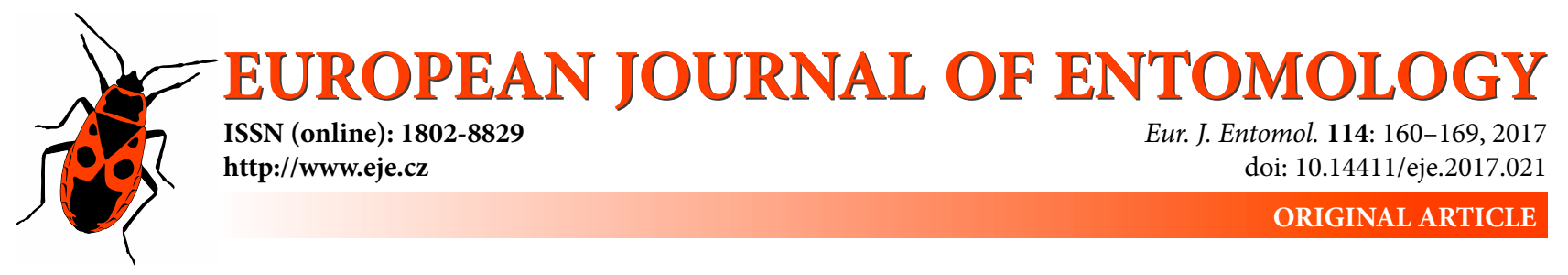

\title{
An early suitability assessment of two exotic Ophraella species (Coleoptera: Chrysomelidae) for biological control of invasive ragweed in Europe
}

\author{
SuzAnne T.E. LOMMEN ${ }^{1}$, Emilien F. JOLIDON ${ }^{1}$, YAN SUN ${ }^{1,2}$, José I. BUSTAMANTE EDUARDO ${ }^{1}$ \\ and HEINZ MÜLLER-SCHÄRER ${ }^{1}$ \\ ${ }^{1}$ Dept. of Biology, University of Fribourg, Chemin du Musée 10, CH-1700 Fribourg, Switzerland; \\ e-mails: suzanne.lommen@unifr.ch, emilien.jolidon@gmail.com, yan.sun@unifr.ch, jose.bustamanteeduardo@unifr.ch, \\ heinz.mueller@unifr.ch \\ ${ }^{2}$ Plant Evolutionary Ecology, Institute of Evolution \& Ecology, University of Tübingen, Auf der Morgenstelle 5, \\ D-72076 Tübingen, Germany
}

Key words. Coleoptera, Chrysomelidae, Ophraella, biological control, invasive plant, Ambrosia artemisiifolia

Abstract. Classical biological control is an important means of managing the increasing threat of invasive plants. It constitutes the introduction of natural enemies from the native range of the target plant into the invaded area. This method may be the only cost-effective solution to control the rapidly expanding common ragweed, Ambrosia artemisiifolia, in non-crop habitats in Europe. Therefore, candidate biocontrol agents urgently need to be assessed for their suitability for ragweed control in Europe. A previous literature review prioritized the host-specific leaf beetle Ophraella slobodkini as a candidate agent for ragweed control in Europe, whereas it rejected its oligophagous congener O. communa. Meanwhile, O. communa was accidentally introduced and became established south of the European Alps, and we show here that it is expanding its European range. We then present a short version of the traditional pre-release risk-benefit assessment for these two candidate agents to facilitate fast decision-making about further research efforts. We selected two complementary tests that can be conducted relatively rapidly and inform about essential risks and benefits. We conducted a comparative no-choice juvenile performance assay using leaves of ragweed and sunflower, the most important non-target plant, in Petri dishes in climatic conditions similar to that in the current European range of $O$. communa. This informs on the fundamental host range and potential for increasing abundance on these host plants. The results confirm that $O$. slobodkini does not survive on, and is hence unlikely to cause severe damage to sunflower, while $O$. communa can survive but develops more slowly on sunflower than on ragweed. In parallel, our species distribution models predict no suitable area for the establishment of $O$. slobodkini in Europe, while $O$. communa is likely to expand its current range to include a maximum of $18 \%$ of the European ragweed distribution. Based on this early assessment, the prioritization and further assessment of $O$. slobodkini seem unwarranted whereas the results urgently advocate further risk-benefit analysis of $O$. communa. Having revealed that most of the European area colonized by ragweed is unlikely to be suitable for these species of Ophraella we suggest the use of such relatively short and cheap preliminary assessment to prioritise other candidate agents or strains for these areas.

\section{INTRODUCTION}

Invasions by alien plant species are increasing in frequency and severity (Lambdon et al., 2008; Early et al., 2016). The deployment of classical biological control (BC) may be an important, and often the only, option for managing areas that are too large or too sensitive to be subjected to chemical or mechanical control (van Wilgen et al., 2013; Seastedt, 2015). In classical weed BC specialised antagonists, often from the plant's native range, are released into the invaded range. The introduced antagonists should establish stable populations and provide sustainable control by suppressing the abundance of the target plant below economic or ecological thresholds, while being of limited ecological risk in the introduced area (Müller-Schärer \&
Schaffner, 2008). Classical weed BC is a permanent, environmentally friendly and cost-effective management tool (Culliney, 2005; van Wilgen et al., 2013; Suckling \& Sforza, 2014). It has successfully been used on several continents in the last 150 years (Winston et al., 2014), but only very recently in Europe (Shaw et al., 2016).

Modern classical weed BC programs follow a well-established procedure (Briese, 2000, 2004). After identification of the target weed and the exploration of candidate agents, the latter are prioritised by assessing their expected efficacy in controlling the target plant and their safety with respect to non-targets, often based on published information. More specific agents are assumed to decrease the risks of non-target attack, and increase the probability of control 
success (Briese, 2004). The prioritized candidate agents are then subjected to an extended pre-release assessment of the potential direct and indirect risks (e.g. for non-target species) and benefits (e.g. impact on target), including rigorous experimentation and modelling (Louda et al., 2003; Thomas \& Reid, 2007). The results are needed in order to petition for them to be released into the invaded environment, which is usually evaluated by the national competent authorities of the countries concerned. The regulation in Europe is currently still complex because each country has different laws, which are not designed for the introduction of beneficials (Shaw, 2008; Shaw et al., 2011), but the new EU Regulation 1143/2014 on Invasive Alien Species may stimulate adaptation and harmonisation of the regulations (Shaw et al., 2016).

Common ragweed, Ambrosia artemisiifolia L. (Asteraceae), originates from North America (Bassett \& Crompton, 1975) and has become a widespread invader on several other continents, including Europe. This annual monoecious plant is a pioneer species that can grow in a wide range of habitats and climates (Essl et al., 2015). As it is an important aeroallergen and crop weed it causes serious harm to our society. Common ragweed's spread (Essl et al., 2015) and impact (Hamaoui-Laguel et al., 2015) are expected to increase under climate change. While herbicide treatments and mechanical controls have been developed and implemented as short-term measures (Buttenschøn et al., 2009), they do not provide sufficient control in the long term, and are not suitable or too costly in most habitats invaded by common ragweed. Biological control may be the only cost-effective solution providing long-term control. This method has indeed already been successfully implemented on other continents. In China successful ragweed control is provided by the stem-galling moth Epiblema strenuana (Walker) and the leaf-feeding beetle Ophraella communa LeSage (Zhou et al., 2011a, b), and in Australia by E. strenuana and the leaf-feeding beetle Zygogramma bicolorata Pallister (Palmer \& Goeden, 1991). There is, therefore, an urgent need to investigate the option of classical BC for ragweed control in Europe.

An earlier literature review prioritized six exotic specialised insect species as candidates for classical BC of ragweed in Europe (Gerber et al., 2011). The chrysomelid beetle Ophraella slobodkini Futuyma was among them, mainly because of its reported very narrow fundamental host range. Species of the family Chrysomelidae have so far been most successful in BC programs of invasive weeds worldwide compared to other insect taxa (Clewley et al., 2012). The species itself was only described in 1991, and mainly occurs in Florida, in a subtropical climate (Futuyma, 1991). It has never been used as a BC agent against ragweed, and little is known about its potential impact. A risk-benefit assessment of this species was therefore considered highly desirable (Gerber et al., 2011). Its congener O. communa, in contrast, has already performed well as an inundative BC agent of ragweed in crop fields in Canada (Teshler et al., 2002) and more recently in an inoculative approach in China (Huang et al., 2011; Zhou et al., 2011a, b).
It originates from warm temperate and subtropical climates in North America (LeSage, 1986). The larvae as well as the adults feed preferentially on $A$. artemisiifolia (Yamazaki et al., 2000). If densities of the beetle are high they can cause early mortality before plants become reproductive, or, if plants manage to survive until reproduction, reduce their seed production (Zhou et al., 2014). The beetle is capable of unassisted dispersal over hundreds of kilometres per year (Moriya \& Shiyake, 2001). Given its potential impact on common ragweed, $O$. communa had already been mentioned as the most promising candidate $\mathrm{BC}$ agent for Europe by Kiss (2007). It was, however, not regarded as a candidate by Gerber et al. (2011) for Europe and had earlier been rejected as a candidate for Australia because of its wider fundamental host range including sunflower (Palmer \& Goeden, 1991). Feeding on sunflower and a few other plant species from the same tribe (Heliantheae) has indeed been reported based on results from no-choice tests in the laboratory (Palmer \& Goeden, 1991; Cao et al., 2011), and from field surveys after its accidental introduction into Japan (Yamazaki et al., 2000). Although release has not been petitioned for to date in Europe, O. communa was detected in Europe in 2013: it was found to have established south of the European Alps, in the Swiss canton of Ticino and several regions of Northern Italy where it caused severe defoliation of ragweed (Müller-Schärer et al., 2014). Since then, O. communa has continued to spread (Fig. 1A) (see also Augustinus et al., 2015). Recent aerobiological studies in Northern Italy indicate that it has already contributed to reduced levels of airborne ragweed pollen since 2013 (Bonini et al., 2015a,b). An evaluation of its suitability as BC agent in Europe is urgently needed to help local and national authorities decide on how to react to its presence (Müller-Schärer et al., 2014). In both species of Ophraella, gravid females prefer to feed and oviposit on A. artemisiifolia, and the three larval stages also feed on this species until they pupate on their host or neighbouring plants (Futuyma, 1990). Both species are multivoltine and the adults overwinter on other plant species (Futuyma, 1990; Watanabe \& Hirai, 2004).

Delivering a complete pre-release risk-benefit analysis such as needed for a petition for the release of a weed BC agent can take up to ten years and is expensive (Moran et al., 2005). This is partially due to currently common riskadverse "precautionary" approach towards the introduction of exotic species (Sheppard, 2003). The risk assessment in weed $\mathrm{BC}$ has historically mainly focussed on the direct risks for non-target plants (Müller-Schärer \& Schaffner, 2008), inferred from protocolled experiments on host specificity (Briese, 2004; Sheppard et al., 2005; Barratt et al., 2010). Nowadays, rigorous host-specificity testing on tens of non-target species is often demanded, which alone can take up to ten years. The assessment of benefits remains a scientific challenge, as the success of control agents in BC programs is highly context-dependent (van Klinken \& Raghu, 2006). Spatially-explicit demographic models can help to predict the long-term effect of $\mathrm{BC}$ at the population level, but this requires detailed data on the demography, 


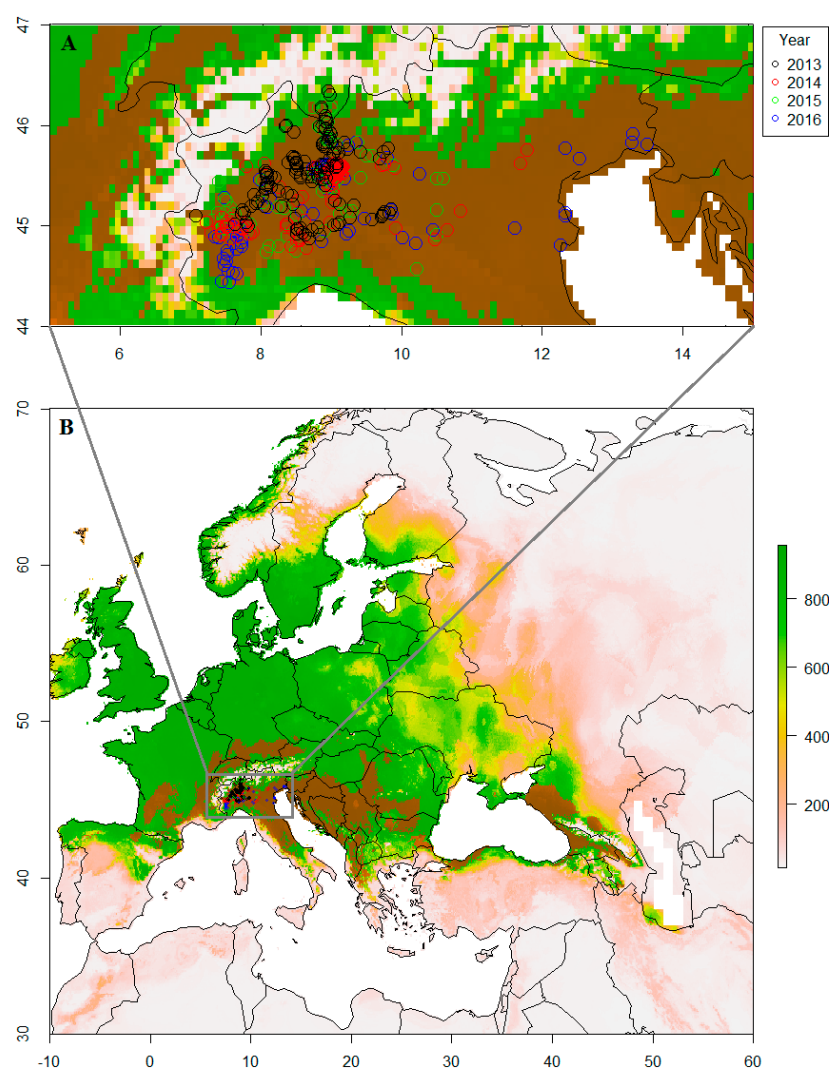

Fig. 1. Map showing the presence in Europe of $O$. communa recorded between 2013 and 2016 as circles in different colours for different years $(A)$, which shows that the range of this species is increasing. Projected climatic suitability for O. communa in Europe under current climatic conditions is indicated in brown and covers $18 \%$ of the projected area suitable for $A$. artemisiifolia indicated by different colours, from unsuitable in light red via medium suitability in yellow, to suitable in green (B, modified from Sun et al., 2017)

spread and density-dependent interactions of the species involved and has rarely been done (Raghu et al., 2006; Barratt et al., 2010; Hahn et al., 2012). Researchers as well as authorities are likely to have to decide quickly about investing in ragweed $\mathrm{BC}$ agents in Europe. In this paper, we present a short version of the traditional pre-release risk-benefit assessment to quickly evaluate if the candidate agents $O$. slobodkini and $O$. communa are worth being subjected to further in-depth risk-benefit assessments.

\section{MATERIAL AND METHODS}

\section{Designing a rapid preliminary risk-benefit assessment for Ophraella spp.}

We selected two different aspects of the traditional risk-benefit assessment that are crucial for determining the suitability of a BC agent, which can also be relatively easily and quickly assessed. The first aspect is the capability of larvae to complete their development to the adult stage on a host plant, and the speed with which they complete their development. Larval performance is a major focus of host specificity testing next to female oviposition preference, but is easier to measure than female behaviour. From the wide range of possible tests, we chose a no-choice laboratory experiment, which is the most stringent non-target host plant risk assessment possible. It specifies the genetically determined fundamental host range, i.e. the range of hosts on which a herbivore is able to complete its life cycle, or at least parts thereof (van Klinken \& Heard, 2000; van Klinken \& Edwards, 2002). If they cannot complete their development, herbivores will fail to build up populations on that species. The underlying assumption is that phylogenetically more closely related species are at higher risk (Wapshere, 1974). The speed of development is also informative, since faster herbivore development allows faster population build-up, which is likely to result in high densities of populations of the herbivore and large effects. The laboratory setting allowed the mimicking of European temperature regimes. It is known that the host range of Ophraella is restricted to the family Asteraceae (Futuyma \& McCafferty, 1990). We limited the test to a European variety of the sunflower, Helianthus annuus L., the non-target species most at risk due to its close phylogenetic relationship to A. artemisiifolia (both are in the tribe Heliantheae) and its economic importance.

The second aspect we selected is the capacity of the agent to establish in the geographic target area, a prerequisite for successful biocontrol. The percentage of the predicted geographic range of the target weed potentially covered by the agent provides an indication of the potential extent of BC success (Kriticos, 2003) and of the geographical area at risk of non-target effects. This percentage cover can be assessed by modelling the predicted suitable range of both the target weed and the $\mathrm{BC}$ agent in the area of release. Species distribution models (SDMs) are a common tool used to predict species distributions based on environmental similarities. Generally, SDMs use data on species-level biogeography and ecology, relate these to environmental space, and map likely species distributions, under current or possible future conditions (Booth et al., 2014). The specific modelling methodology chosen depends on the system studied and the availability of suitable data. We used a climatic suitability modelling approach to make predictions about the climatic suitability of the target area for ragweed and both candidate species of Ophraella (van Klinken \& Raghu, 2006), based on the similarity between the climate in the target area and the climate of present worldwide occurrences of these species (Elith et al., 2006). This method is often used to assess the potential geographic ranges of introduced alien species (Broennimann \& Guisan, 2008; Peterson et al., 2008; Villemant et al., 2011) since occurrence data can usually be retrieved from the literature and climatic data are available online.

We argue that combining the two aspects is essential for a robust preliminary evaluation. The juvenile performance assay allows the risk for a particular species of non-target host plant to be assessed under similar conditions to those in the target area, but such experiment can only include a limited number of host plants and set of environmental conditions. Climatic suitability modelling, in contrast, reflects a more integrated ecological approach, identifying the potential geographic area where the candidate agents, and hence associated risks and benefits, may occur.

\section{Juvenile performance experiment}

\section{Material}

A permission to import and work with the exotic organisms in the greenhouse and/or quarantine facilities of the University of Fribourg, Switzerland, was issued by the Swiss Federal Office for the Environment (A130598-3). Plants of A. artemisiifolia of mixed origins (European and USA) and sunflowers (Helianthus annuus PR64H42, a variety grown notably in Ticino, Switzerland, where $O$. communa is established) were grown from seeds in a greenhouse $(16 \mathrm{~L}: 8 \mathrm{D}$ photoperiod with minimum temperatures of $25 / 17^{\circ} \mathrm{C}$ ). We collected ca. 150 adults of $O$. slobodkini in Florida, USA, in June 2014, that were then imported and maintained in culture on ragweed in the quarantine facilities (14L: 10D photoperiod with $25 / 16 \pm 1.5^{\circ} \mathrm{C}$ ). About 150 egg batches of $O$. communa were directly collected from wild ragweed in Abbi- 
ategrasso and Magnago, northern Italy, in early April 2015, and brought into the same facilities for use in the experiment. From each species of beetle, single egg batches were checked daily for hatching in April 2015.

\section{Experimental procedure}

We measured juvenile performance of the beetles in a no-choice experiment by placing first instar larvae on detached leaves in Petri dishes. This takes up less space and requires fewer plants, allowing for more replicates, than when using entire plants. We acknowledge that detached leaves might affect larval performance through an altered physiology (Smith \& Beck, 2013), but our focus here is a comparative one. We assessed each species of beetle on ragweed or sunflower under two different European temperature regimes in a full factorial design with 15 replicates. Hence, we had eight experimental groups (two beetle species $x$ two host plants $\times$ two temperatures) with 15 larvae each, using 60 larvae of each beetle species in total. We maximised the likelihood of host plant acceptance by avoiding competition and providing fresh food ad libitum. The experiment started in mid-April 2015. Both Ophraella species originate from climates that are hotter than most European climate and it is unknown how European climates affect their performance. Therefore, we used two experimental conditions representing conditions in the European area currently colonized by $O$. communa. We used four incubators (Panasonic Healthcare Co, MIR-154-PE), two of which were set to "cool" condition, corresponding to spring conditions in the currently colonized range (14L: $10 \mathrm{D}$ at $\left.19.6 / 11.6 \pm 0.3^{\circ} \mathrm{C}\right)$, and two to "warm" condition, corresponding to summer conditions in that area $\left(16 \mathrm{~L}: 8 \mathrm{D}\right.$ at $\left.26.0 / 17.5 \pm 0.3^{\circ} \mathrm{C}\right)$. Leaves were detached from ragweed and sunflower plants, rinsed with sterilized water and then individually placed onto moist filter paper in a Petri dish. Within $24 \mathrm{~h}$ after hatching, the first instar larvae (L1) were randomly assigned to one of the four experimental treatments (one of the host plants and one of the climatic conditions), and then individually transferred into the middle of the leaf in their own Petri dish with a fine brush. Dishes were closed with parafilm to prevent the larvae from escaping and keep the conditions inside moist. They were placed into one of the incubators of the allocated climatic condition and regularly moved within and between incubators with the same climatic condition. Leaves were replaced twice a week, or more frequently if they became unsuitable. The filter paper was also replaced regularly to avoid fungus proliferating. All larvae used hatched within one week from 9 egg batches of $O$. communa and 10 of $O$. slobodkini. Of each batch, on average $6.3 \pm 3.5$ larvae were used. To avoid bias by egg batch origin, each of the eight experimental groups included larvae from 6-8 different egg batches of each species of beetle. Survival and development of the transferred larvae was monitored daily. Moulting to the next instar was checked by recording shed larval skins and the sex of eclosing adults was visually determined (Guo et al., 2010). The experiment stopped when all larvae had either died or developed into adults.

\section{Statistical analysis}

The statistical analysis using $\mathrm{R}$ (version 3.1.2, R Core Team, 2014) involved making linear mixed effects models of the total development time from L1 to the adult stage using the lmer function in the package "Ime4" (Bates et al., 2015). We defined a full model (including beetle species, plant species and climatic conditions, and all their relevant interactions as fixed effects, and egg batch identity as a random effect on the intercept) with a Gaussian error distribution using an identity link function. We fitted the model using the Restricted Maximum Likelihood (REML) method and visually inspected the residual plots. We then similarly formulated 12 additional simpler models, by deleting all possible combinations of fixed factors and their interactions, but always keeping the random effect. We then fitted all these 13 models using the Maximum Likelihood method in order to obtain likelihood estimates. We ordered the models according to their likelihood, using the modified Akaike Information Criterion (AICc), which penalises the inclusion of extra parameters, to adjust for the relatively small sample size (Burnham \& Anderson, 2002), and calculated the evidence ratio of the best model compared to each of the lower-ranked models (Burnham et al., 2011). We rejected all models with $\triangle \mathrm{AICc}>6$ compared to the best model (this is a conservative threshold, Richards, 2005), and additionally, to adhere to the principle of parsimony, those with $\triangle \mathrm{AICc}$ values $<6$ but including more parameters than the best model. We finally used the (single) remaining model with an REML fit to obtain estimates and confidence intervals of development time for each of the experimental groups. We assessed the goodness of fit calculating the conditional $\mathrm{R}^{2}$, which takes random variance into account, following Nakagawa \& Schielzeth (2013).

\section{Species distribution model}

\section{Species occurrences and bioclimatic data}

We collected all occurrences recorded for A. artemisiifolia, $O$. slobodkini and O. communa worldwide (see Supplementary Information 2 for sources and collection methods). We used WORLDCLIM to obtain climate data on current conditions at a spatial resolution of $5 \mathrm{~min}$ (www.worldclim.org/bioclim, Hijmans et al., 2005). To derive a set of predictors that are critical for survival and physiological functions for each of the species, we evaluated the importance of these 19 climatic variables and the derived variable growing degree days [GDD; using GDD > $8^{\circ} \mathrm{C}$ for $A$. artemisiifolia based on this threshold for the closely related sunflower (Sadras \& Hall, 1988), and GDD $>10^{\circ} \mathrm{C}$ for the beetles, because this is the most common lower threshold for development for insects (Pruess, 1983)]. Response curves reveal how the model's predictions change as the bioclimatic variables varied and those that did not affect the predictions were deleted. The climatic variables eventually chosen for each species are listed in the Supplementary Information 2, Table S3.

\section{Statistical modelling}

Duplicated occurrences within a raster pixel were removed. As only occurrences were available, we generated 10,000 random pseudo-absences to fill the absence component in the models (Barbet-Massin et al., 2012). Current climates were projected for each species using the Biomod2 framework (Thuiller et al., 2009, 2013) and a combination of different modelling techniques to find the optimal solution for dealing with the inherent uncertainty of each of these models (Araujo \& New, 2007) and the discrepancies resulting from using different techniques. The Biomod2 platform accounts for inter-model variability by fitting ensembles of forecasts and analysing the resulting range of uncertainties using bounding box, consensus and probabilistic methodologies (Araujo \& New, 2007; Thuiller et al., 2009). For each of the species, generalized linear models (GLM), generalized boosting models and maximum entropy models (MAXENT) were calibrated on a random sample of the initial data $(80 \%)$, and then tested using the remaining data $(20 \%)$ using both the receiver-operating characteristic curve and true kill statistic (Pearce \& Ferrier, 2000). To balance under-fitting with overfitting predictions, we simplified the model based on the Bayesian Information Criterion for GLM and used the same setting of the regularization parameter $\beta$ in MAXENT for all feature types ( $\beta$ was caculated based on the number of presence data we used in the model) (Merow et al., 2014). We then estimated the response curves. The above tech- 


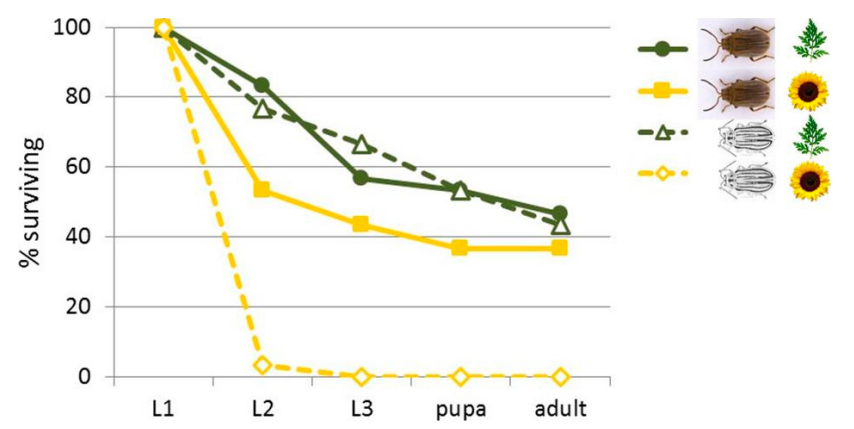

Fig. 2. Percentage survival of the two ragweed leaf beetles $(O$. communa: solid lines with filled symbols; O. slobodkini: dashed lines with open symbols) during their juvenile development (L1L3 represent larval instars 1-3) on ragweed (dark) and sunflower (light). Data for the two experimental conditions are pooled since they did not affect survival (hence $100 \%$ represents $N=30$ ).

niques were chosen because they reveal the most effective SDMs (Elith et al., 2006). The whole training-evaluation procedure was repeated 25 times for each model, using a different set of initial data in each replicate, to ensure robustness of the predictions and provide uncertainty estimates (Broennimann \& Guisan, 2008). We also measured the non-analogous environments between the study area used to calibrate the SDMs and the projected area for the SDMs, and removed all non-analogous climates in the final prediction to avoid extrapolation of models beyond training conditions (Mesgaran et al., 2014). The predictive power of the models was tested using the area under the receiver-operator characteristic function (area under the curve criteria, AUC) for evaluation (Pearce \& Ferrier, 2000). Given the high AUC values (>0.8) (van Proosdij et al., 2016) of each modelling approach for all species, the predictions of the models are robust. In order to visually overlay the insects distributions on that of $A$. artemisiifolia, the probabilities of presence of the insects were then binary transformed into presences and absences for each raster pixel (see details in Sun et al., 2017).

\section{RESULTS}

\section{Juvenile performance}

Not a single $O$. slobodkini larva survived on sunflower and all but one died in the first larval stage. In all the other experimental groups, nearly half of the 15 larvae developed into adults, regardless of beetle species, host plant or temperature (Fig. 2). Whereas mortality on sunflower occurred mainly in the first larval stage, mortality on ragweed occurred in all stages (Fig. 2). In total 12 males, 11 females, and one adult of unknown sex were recorded for O. communa, and 5, 7 and 1 for $O$. slobodkini, respectively, which do not deviate significantly from the expected $1: 1$ sex ratio. Both sexes occurred in all treatments in which adults developed.

The best statistical model for the total development time from L1 to the adult stage included in addition to the random effect of egg batch identity, the main effects of species of beetle, plant and conditions, and the interaction between species of beetle and conditions, and explained $96.5 \%$ of the total variance (see details of all models in Supplementary Information 1, Table S1). The fastest development of about 3 weeks was recorded for $O$. communa on ragweed in "warm" conditions, whereas $O$. slobodkini took nearly 4 weeks (24\% longer than O. communa) (Fig. 3). Develop-

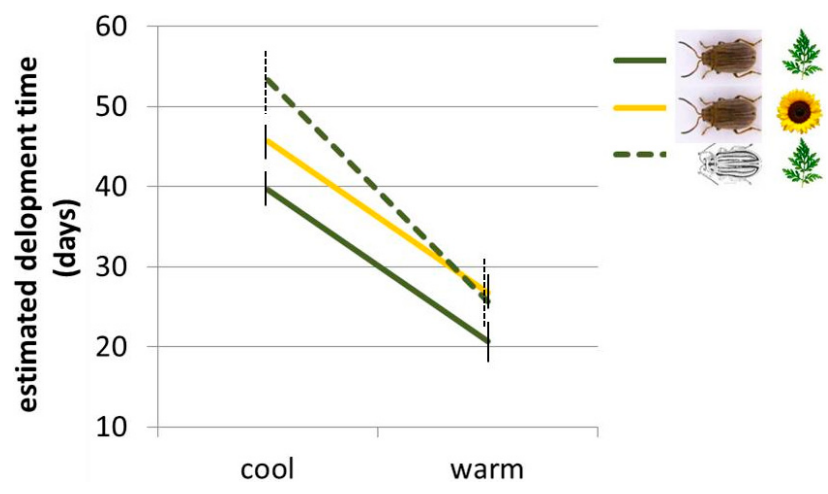

Fig. 3. Interaction plot depicting the development time from $L 1$ to adults for all of the 38 adults that developed of the two species of ragweed leaf beetles ( $O$. communa solid lines, O. slobodkini dashed line) on ragweed (dark) and sunflower (light) under two different conditions (cool, 14L: 10D at $19.6 / 11.6^{\circ} \mathrm{C}$; warm, $16 \mathrm{~L}: 8 \mathrm{D}$ at $26.0 / 17.5^{\circ} \mathrm{C}$ ). Values recorded in each of the two conditions are estimated development times and their 5-95\% confidence intervals based on the best fitting linear mixed model, whereas the connecting lines only serve to visualise the interactions (there is an interaction between beetle species and condition, but not between plant species and condition).

ment time approximately doubled in the cool conditions in which that of $O$. slobodkini was $32 \%$ longer than that of O. communa. Ophraella communa developed significantly slower (ca. 15\% longer) on sunflower than on ragweed in both warm and cool conditions. The development times of each of the different stages were strongly correlated with the total development time (Supplementary Information 1, Table S2), and the proportion of the time spent in each stage was similar in all the groups (Supplementary Information 1, Fig. S1).

\section{Species distribution model}

The occurrence data yielded 5018, 541, and 36 worldwide raster pixels for the presence of $A$. artemisiifolia, $O$. communa and $O$. slobodkini, respectively. The evaluation of climatic variables resulted in the selection of GDD, along with 2-8 different bioclimatic variables for each of the species (Supplementary Information 2, Table S3). Fig. $1 \mathrm{~B}$ presents the projected climatic suitability for $O$. communa, overlain on the predicted range of A. artemisiifolia. Ophraella communa is predicted to be able to colonize a much larger area than currently (Fig. 1A), extending to the Mediterranean and even north of the Alps, and, in addition, areas around the Black Sea (Fig. 1B). Together, this would include $18 \%$ of the predicted range of $A$. artemisiifolia under current climatic conditions. In contrast, the climate in Europe seems to be unsuitable for Ophraella slobodkini, since there is no geographic area predicted for this species, within or outside the predicted range of $A$. artemisiifolia.

\section{DISCUSSION}

The results of our juvenile performance assay corroborate earlier studies that $O$. slobodkini poses less of a risk to sunflower than O. communa (Gerber et al., 2011). Since none of the larvae of $O$. slobodkini survived on sunflower, we predict that $O$. slobodkini is unable to build up a population on this variety. If eggs are laid on sunflower, damage 
from larvae will be negligible, as only one out of 30 larvae reached the second instar. Paynter et al. (2015) recently report that the ratio of survival on non-target versus target plants in no-choice tests is a good estimate of the probability of non-target plants being attacked in the field. Our results indicate that the probability would be below 5\% (e.g. a spill-over effect of adult beetles reaching high densities on the target plant). Because $O$. communa survived on the sunflower variety used, this sunflower was included in the fundamental host range of $O$. communa. The probability of survival of larvae of $O$. communa was as high on this sunflower as on ragweed, which contrasts with previous studies in which a very low percentage survival is recorded on sunflower compared to ragweed (Dernovici et al., 2006; Cao et al., 2011). The probability of survival is likely to vary with sunflower variety, age and environmental conditions, even though we recorded no effect of temperature on survival. Since the realized host range in the field is usually a subset of the fundamental range (van Klinken \& Heard, 2000), this result requires further investigation under European field conditions (e.g. Briese et al., 2002; Briese, 2005; Sheppard et al., 2005).

The slower development of $O$. communa on sunflower compared to ragweed, in combination with our personal observations that more tissue of sunflower was consumed, strongly indicate that sunflower is a less suitable food source for the larvae than ragweed. This is also likely to result in a slower build-up of beetle populations on sunflower than on ragweed. This is in line with other developmental studies, as Dernovici et al. (2006) predict that O. communa will not increase in abundance on sunflower based on lifetable parameters recorded in a laboratory. Several studies indicate that $O$. communa females prefer A. artemisiifolia for oviposition over other plants, and oviposition on sunflower growing close to ragweed is indeed only very rarely recorded in the field (Dernovici et al., 2006; Cao et al., 2011; Zhou et al., 2011c). Importantly, Ophraella commu$n a$ is not reported as a pest of sunflower in its native North American range (Palmer \& Goeden, 1991). Taken together, despite the ability of $O$. communa larvae to survive on the European sunflower variety tested under European conditions, the risk for sunflower is slight, but this urgently needs to be confirmed in the field in Europe.

The performance of $O$. slobodkini on ragweed under European conditions was poorer than that of $O$. communa in the juvenile performance assay. This indicates that $O$. slobodkini is less well adapted to developing under European conditions, which is not surprising given that the climate in its native range is hotter than that of O. communa (Futuyma, 1991). The climatic suitability modelling resulted in even more distinct patterns for these two species of beetles. According to the model predictions based on climate, no region in Europe is currently suitable for O. slobodkini. We acknowledge the uncertainty of the model due to the few records of the occurrence of this species (van Proosdij et al., 2016) in a small geographic area (in and around Florida). It is also possible that historical records of Ophraella occurrence from elsewhere were misidentified and include the recently recognized $O$. slobodkini and that this species is more widespread in North America. The current range of Ophraella communa in Europe, in contrast, is likely to increase in all directions by hundreds of kilometres. The model indicates also that its potential range is restricted to the $50^{\circ}$ latitude and further expansion west and east is limited to only maximum $18 \%$ of the potential ragweed distribution in Europe (Fig. 1B).

\section{Directions for future research on agent selection and testing}

Despite our confirmation that $O$. slobodkini will not develop on sunflower, we reject the prioritisation of this species as a BC agent for use in Europe since our distribution model indicates that no part of Europe is currently suitable for this species. As a consequence, we recommend focusing the research effort on other species. In contrast, we advocate further risk-benefit analysis of the formerly rejected $O$. communa. The juvenile performance experiment revealed that this species can develop under European conditions, confirms there is a potential risk of it attacking sunflower, and indicates that this species is potentially capable of building up populations on ragweed. The distribution model highlights the need for an assessment for an area larger than that currently colonized by $O$. communa and that the ongoing expansion of this species highlights the urgency of such an assessment. Follow-up studies on $O$. communa should weigh potential benefits against potential risks, and compare these with the impact of $A$. artemisiifolia in the absence of BC agents (van Wilgen et al., 2013). Therefore, more extensive host-range tests including oviposition and feeding tests under choice and no-choice conditions with various developmental stages and varieties of sunflower, and other plant species, both in the laboratory and in the field, are needed. Impact studies should assess its potential effect on $A$. artemisiifolia population growth and pollen production in relation to beetle density, plant phenology and climate.

Since it is very likely that $O$. communa will spread to the other climatically suitable areas in Europe (Fig. 1B) (Pratt \& Center, 2012), our results may also be used to alert authorities in the specified areas to the potential future establishment of $O$. communa in their area. Based on our findings, the French Agency for Food, Environmental and Occupational Health \& Safety has already created an Expert Group to conduct a Pest Risk Analysis (Anses, 2015) and recently also a Benefit Analysis for O. communa in France, where the species does not currently occur.

Our results indicate no establishment or lower performance of O. communa in the cooler areas in Europe. Natural spread to such areas, however, might be facilitated by future changes in climate (Sun et al., 2017), or the species may quickly adapt to current conditions. Evidence for rapid adaptation in the field comes from Japan, where $O$. communa adapted to the shorter day length in more northern areas by a shift in the critical day length inducing diapause (Tanaka et al., 2014). Limited performance may be partially overcome by increasing densities by augmentative releases early in the season (as is practiced in China, 
Zheng et al., 2011), or by developing cold-resistant strains by selective breeding of suitable genotypes or through acclimation (Zhou et al., 2013). Alternatively, other agents may be needed for these areas.

\section{CONCLUSION}

We have shown that this rapid preliminary risk-benefit assessment proved useful in shifting research focus from the formerly prioritized candidate $O$. slobodkini to the formerly rejected and less specific congener $O$. communa for ragweed control in Europe. It also helped to identify the need for other BC agents for use in the cooler parts of Europe. We strongly advocate the use of a rapid procedure (but adapted to the species under study) for further use in the prioritization of other $\mathrm{BC}$ candidates of ragweed in Europe.

ACKNOWLEDGEMENTS. We thank J. Romanens for rearing plants and insects, Y. Fukano for practical advice on the experimental set up, C. Leuba for help in data collection, O. Broennimann, B. Petitpierre and R. Rohr for advice on spatial modelling and statistics, and U. Schaffner and multiple anonymous reviewers for critical comments on earlier versions of the manuscript. We acknowledge financial support from the Federal Office for the Environment (13.0098.KP/M323-0760), the Federal Office for Agriculture (1062-62200), the Swiss State Secretariat for Education, Research and Innovation (C13.0146 to HMS) and the EU COST Action FA1203 "Sustainable management of Ambrosia artemisiifolia in Europe (SMARTER)".

\section{REFERENCES}

ANSEs 2015: Évaluation des Risques pour la Santé des Végétaux Liés à l'Introduction Accidentelle ou en tant qu'Agent de Lutte Biologique, d'Ophraella communa, un Insecte Ravageur de l'Ambroisie à Feuilles d'Armoise. Anses (Agence nationale de sécurité sanitaire de l'alimentation, de l'environnement et du travail), Maisons-Alfort, $64 \mathrm{pp}$.

Araujo M.B. \& New M. 2007: Ensemble forecasting of species distributions. - Trends Ecol. Evol. 22: 42-47.

Augustinus B., Guarino M., Colombo F., Citterio S., Schaffner U., Müller-Schärer H. \& Gentili R. 2015: Nuove segnalazioni di Ambrosia artemisiifolia e Ophraella communa in Valtellina (Alpi Centrali, Lombardia). - Natura Bresciana / Ann. Mus. Civ. Sci. Nat. Brescia 39: 45-48.

Barbet-Massin M., Jiguet F., Albert C.H. \& Thuiller W. 2012: Selecting pseudo-absences for species distribution models: how, where and how many? - Meth. Ecol. Evol. 3: 327-338.

Barratt B.I.P., Howarth F.G., Withers T.M., Kean J.M. \& RidLEY G.S. 2010: Progress in risk assessment for classical biological control. - Biol. Contr. 52: 245-254.

Bassett I.J. \& Crompton C.W. 1975: The biology of Canadian weeds: Ambrosia artemisiifolia L. and A. psilostachya DC. Can. J. Plant Sci. 55: 463-476.

Bates D., Maechler M., Bolker B.M. \& Walker S.C. 2015: Fitting linear mixed-effects models using lme4. - J. Stat. Softw. 67: $1-48$.

Bonini M., Sikoparija B., Prentovic M., Cislaghi G., Colombo P., Testoni C., Grewling L., Lommen S.T.E. \& Mueller-SchaerER H. 2015a: A follow-up study examining airborne Ambrosia pollen in the Milan area in 2014 in relation to the accidental introduction of the ragweed leaf beetle Ophraella communa. - Aerobiologia 32: 371-374.
Bonini M., Sikoparija B., Prentovic M., Cislaghi G., Colombo P., Testoni C., Grewling L., Lommen S.T.E., Mueller-Schaerer H. \& Sмітн M. 2015b: Is the recent decrease in airborne Ambrosia pollen in the Milan area due to the accidental introduction of the ragweed leaf beetle Ophraella communa? - Aerobiologia 31: 499-513.

Bоoтh T.H., Nix H.A., Busby J.R. \& Hutchinson M.F. 2014: BIOCLIM: the first species distribution modelling package, its early applications and relevance to most current MAXENT studies. - Divers. Distrib. 20: 1-9.

BRIESE D.T. 2000: Classical biological control. In Sindel B. (ed.): Australian Weed Management Systems. RG \& FJ Richardson, Melbourne, pp. 161-192.

BRIESE D.T. 2004: Weed biological control: applying science to solve seemingly intractable problems. - Aust. J. Entomol. 43: 304-317.

BRIESE D.T. 2005: Translating host-specificity test results into the real world: The need to harmonize the yin and yang of current testing procedures. - Biol. Contr. 35: 208-214.

Briese D.T., Zapater M., Andorno A. \& Perez-Camargo G. 2002: A two-phase open-field test to evaluate the host-specificity of candidate biological control agents for Heliotropium amplexicaule. - Biol. Contr. 25: 259-272.

Broennimann O. \& Guisan A. 2008: Predicting current and future biological invasions: both native and invaded ranges matter. Biol. Lett. 4: 585-589.

Burnham K.P. \& Anderson D.R. 2002: Model Selection and Multimodel Inference: A Practical Information-theoretic Approach. 2 ed. Springer, New York, 515 pp.

Burnham K.P., ANDERson D.R. \& HuYvaerT K.P. 2011: AIC model selection and multimodel inference in behavioral ecology: some background, observations, and comparisons. Behav. Ecol. Sociobiol. 65: 23-35.

Buttenschøn R.M., WaldispüHL S. \& Bohren C. 2009: Guidelines for Management of Common Ragweed, Ambrosia artemisiifolia. Available from www.EUPHRESCO.org, $53 \mathrm{pp}$.

Cao Z., Wang H., Meng L. \& Li B. 2011: Risk to nontarget plants from Ophraella communa (Coleoptera: Chrysomelidae), a potential biological control agent of alien invasive weed $\mathrm{Am}$ brosia artemisiifolia (Asteraceae) in China. - Appl. Entomol. Zool. 46: 375-381.

Clewley G.D., Eschen R., Shaw R.H. \& Wright D.J. 2012: The effectiveness of classical biological control of invasive plants. -J. Appl. Ecol. 49: 1287-1295.

Culliney T.W. 2005: Benefits of classical biological control for managing invasive plants. - Cr. Rev. Plant Sci. 24: 131-150.

Dernovici S.A., Teshler M.P. \& Watson A.K. 2006: Is sunflower (Helianthus annuus) at risk to damage from Ophraella communa, a natural enemy of common ragweed (Ambrosia artemisiifolia)? - Biocontr. Sci. Techn. 16: 669-686.

Early R., Bradley B.A., Dukes J.S., Lawler J.J., Olden J.D., Blumenthal D.M., Gonzalez P., Grosholz E.D., Ibañez I., Miller L.P. ET AL. 2016: Global threats from invasive alien species in the twenty-first century and national response capacities. - Nature Commun. 7: 12485, 9 pp.

Elith J., Graham C.H., Anderson R.P., Dudik M., Ferrier S., Guisan A., Hijmans R.J., Huettmann F., Leathwick J.R., LeHMANN A. ET AL. 2006: Novel methods improve prediction of species' distributions from occurrence data. - Ecography 29: $129-151$.

Essl F., Biró K., Brandes D., Broennimann O., Bullock J.M., Chapman D.S., Chauvel B., Dullinger S., Fumanal B., Guisan A. ET AL. 2015: Biological flora of the British Isles: Ambrosia artemisiifolia. - J. Ecol. 103: 1069-1098. 
FutuYMA D.J. 1990: Observations on the taxonomy and natural history of Ophraella Wilcox (Coleoptera, Chrysomelidae), with a description of a new species. - J. N.Y. Entomol. Soc. 98: $163-186$.

FutuYma D.J. 1991: A new species of Ophraella Wilcox (Coleoptera, Chrysomelidae) from the Southeastern United States. J. N.Y. Entomol. Soc. 99: 643-653.

Futuyma D.J. \& McCafferty S.S. 1990: Phylogeny and the evolution of host plant associations in the leaf beetle genus Ophraella (Coleoptera, Chrysomelidae). - Evolution 44: 1885-1913.

Gerber E., Schaffner U., Gassmann A., Hinz H.L., Seier M. \& MÜLLER-SCHÄRER H. 2011: Prospects for biological control of Ambrosia artemisiifolia in Europe: learning from the past. Weed Res. 51: 559-573.

Guо W., Zнои Z.S. \& Guо J.Y. 2010: Morphological characteristics of Ophraella communa adults. - Plant Prot. 36: 179-182.

Hahn M.A., Buckley Y.M. \& Mueller-Schaerer H. 2012: Increased population growth rate in invasive polyploid Centaurea stoebe in a common garden. - Ecol. Lett. 15: 947-954.

Hamaoui-Laguel L., Vautard R., Liu L., Solmon F., Viovy N., Khyorostyanov D., Essl F., Chuine I., Colette A., Semenov M.A. ET AL. 2015: Effects of climate change and seed dispersal on airborne ragweed pollen loads in Europe. - Nat. Clim. Change 5: 766-771.

Hijmans R.J., Cameron S.E., Parra J.L., Jones P.G. \& Jarvis A. 2005: Very high resolution interpolated climate surfaces for global land areas. - Int. J. Clim. 25: 1965-1978.

Huang S.J., Chen Q., Chen H.S., Qin W.J., Tu X.Q. \& Guo J.Y. 2011: Combined control of Ambrosia artemisiifolia with Ophraella communa (Coleoptera: Chrysomelidae) and Epiblema strenuana (Lepidoptera: Tortricidae) in Nanchang, Jiangxi Province, China. - J. Biosaf. 20: 310-313.

KIss L. 2007: Why is biocontrol of common ragweed, the most allergenic weed in Eastern Europe, still only a hope. In Vincent C., Goettel M. \& Lazarovitz G. (eds): Biological Control: A Global Perspective: Case Studies from around the World. CABI, Wallingford, pp. 80-91.

KRITICOS D.J. 2003: The roles of ecological models in evaluating weed biological control agents and projects. In Spafford-Jacob, H.S. \& Briese D.T. (eds): Improving the Selection, Testing and Evaluation of Weed Biological Control Agents: Proceedings of the CRC for Australian Weed Management Biological Control of Weeds Symposium and Workshop. CRC for Australian Weed Management, Adelaide, pp. 69-74.

Lambdon P.W., Pyšek P., Basnou C., Hejda M., Arianoutsou M., Essl F., Jarošík V., Pergl J., Winter M. \& Anastasiu P. 2008 Alien flora of Europe: species diversity, temporal trends, geographical patterns and research needs. - Preslia 80: 101-149.

LeSAGE L. 1986: A taxonomic monograph of the nearctic galerucine genus Ophraella Wilcox (Coleoptera, Chrysomelidae). Mem. Entomol. Soc. Can. 118: 3-74.

Louda S.M., Pemberton R.W., Johnson M.T. \& Follett P.A. 2003: Nontarget effects - the Achilles' heel of biological control? Retrospective analyses to reduce risk associated with biocontrol introductions. - Annu. Rev. Entomol. 48: 365-396.

Merow C., Smith M.J., Edwards T.C. Jr., Guisan A., McMahon S.M., Normand S., Thuiller W., Wueest R.O., Zimmermann N.E. \& Elith J. 2014: What do we gain from simplicity versus complexity in species distribution models? - Ecography 37: 1267-1281.

Mesgaran M.B., Cousens R.D. \& Webber B.L. 2014: Here be dragons: a tool for quantifying novelty due to covariate range and correlation change when projecting species distribution models. - Divers. Distr. 20: 1147-1159.
Moran V.C., Hoffmann J.H. \& Zimmermann H.G. 2005: Biological control of invasive alien plants in South Africa: necessity, circumspection, and success. - Front. Ecol. Environ. 3: $77-83$.

Moriya S. \& ShiYake S. 2001: Spreading the distribution of an exotic ragweed beetle, Ophraella communa LeSage (Coleoptera: Chrysomelidae), in Japan. — Jap. J. Entomol. 4: 99-102.

MÜLlER-Schärer H. \& SCHAFfNer U. 2008: Classical biological control: exploiting enemy escape to manage plant invasions. Biol. Invas. 10: 859-874.

MÜller-Schärer H., Lommen S.T.E., Rossinelli M., Bonini M., Boriani M., Bosio G., Schaffner U. \& Hatcher P. 2014: Ophraella communa, the ragweed leaf beetle, has successfully landed in Europe: fortunate coincidence or threat? - Weed Res. 54: 109-119.

Nakagawa S. \& Schielzeth H. 2013: A general and simple method for obtaining R2 from generalized linear mixed-effects models. - Meth. Ecol. Evol. 4: 133-142.

Palmer W.A. \& Goeden R.D. 1991: The host range of Ophraella communa LeSage (Coleoptera, Chrysomelidae). - Coleopt. Bull. 45: 115-120.

Paynter Q., Fowler S.V., Gourlay A.H., Peterson P.G., Smith L.A. \& Winks C.J. 2015: Relative performance on test and target plants in laboratory tests predicts the risk of non-target attack in the field for arthropod weed biocontrol agents. - Biol. Contr. 80: 133-142.

Pearce J. \& Ferrier S. 2000: Evaluating the predictive performance of habitat models developed using logistic regression. - Ecol. Model. 133: 225-245.

Peterson A.T., Stewart A., Mohamed K.I. \& Araujo M.B. 2008: Shifting global invasive potential of European plants with climate change. - PLOS ONE 3(6): e2441, 7 pp.

PRAtT P.D. \& CEnTER T.D. 2012: Biocontrol without borders: the unintended spread of introduced weed biological control agents. - Biocontrol 57: 319-329.

PRUESS K.P. 1983: Day-degree methods for pest management. Environ. Entomol. 12: 613-619.

R Core TeAm 2014: $R$ : A Language and Environment for Statistical Computing. R Foundation for Statistical Computing, Vienna. URL: http://www.R-project.org/.

Raghu S., Wilson J.R. \& Dhileepan K. 2006: Refining the process of agent selection through understanding plant demography and plant response to herbivory. - Aust. J. Entomol. 45: 308-316.

RichaRdS S.A. 2005: Testing ecological theory using the information-theoretic approach: Examples and cautionary results. Ecology 86: 2805-2814.

SAdRas V.O. \& Hall A.J. 1988: Quantification of temperature, photoperiod and population effects on plant leaf area in sunflower crops. - Field Crops Res. 18: 185-196.

SEASTEDT T.R. 2015: Biological control of invasive plant species: a reassessment for the Anthropocene. - New Phytol. 205: 490-502.

SHAw R. 2008: Weed biological control regulation in Europe: boring but important. In Julien M.H., Sforza R.F.H., Bon M.C., Evans H.C., Hatcher P.E., Hinz H.L. \& Rector B.G. (eds): Proceedings of the XII International Symposium on Biological Control of Weeds, La Grande Motte, France, 22-27 April 2007. CABI, Wallingford, pp. 484-488.

Shaw R.H., Tanner R., Djeddour D. \& Cortat G. 2011: Classical biological control of Fallopia japonica in the United Kingdom - lessons for Europe. — Weed Res. 51: 552-558.

Shaw R., Schaffner U. \& Marchante E. 2016: The regulation of biological control of weeds in Europe - an evolving landscape. - EPPO Bull. 46: 254-258. 
SHEPPARD A.W. 2003: Prioritising agents based on predicted efficacy: beyond the lottery approach. In Spafford Jacob H. \& Briese D.T. (eds): Improving the Selection, Testing and Evaluation of Weed Biological Control Agents: Proceedings of the CRC for Australian Weed Management Biological Control of Weeds Symposium and Workshop, Perth, Western Australia 13 September 2002. CRC for Australian Weed Management, Glen Osmond, pp. 11-21.

Sheppard A.W., van Klinken R.D. \& Heard T.A. 2005: Scientific advances in the analysis of direct risks of weed biological control agents to nontarget plants. - Biol. Contr. 35: 215-226.

Sмith L. \& BeCK J.J. 2013: Effect of mechanical damage on emission of volatile organic compounds from plant leaves and implications for evaluation of host plant specificity of prospective biological control agents of weeds. - Biocontr. Sci. Techn. 23: 880-907.

Suckling D.M. \& SforzA R.F.H. 2014: What magnitude are observed non-target impacts from weed biocontrol? - PLoS ONE 9(1): e84847, 12 pp.

Sun Y., Broennimann O., Roderick G., Poltavsky A., Lommen S. T.E. \& Mueller-Schaerer H. 2017: Climatic suitability ranking of biological control candidates: a biogeographic approach for ragweed management in Europe. - Ecosphere [in press].

TanaKa K., Murata K. \& MatsuUra A. 2014: Rapid evolution of an introduced insect Ophraella communa LeSage in new environments: temporal changes and geographical differences in photoperiodic response. - Entomol. Sci. 18: 104-112.

Teshler M., DiTommaso A., Gagnon J. \& Watson A. 2002: Ambrosia artemisiifolia L., common ragweed (Asteraceae). In Mason P. \& Huber J. (eds): Biological Control Programmes in Canada, 1981-2000. CABI, Wallingford, pp. 290-294.

Thomas M.B. \& ReID A.M. 2007: Are exotic natural enemies an effective way of controlling invasive plants? - Trends Ecol. Evol. 22: 447-453.

Thuiller W., Lafourcade B., Engler R. \& Araujo M.B. 2009: BIOMOD - a platform for ensemble forecasting of species distributions. - Ecography 32: 369-373.

Thuiller W., Georges D. \& ENGLer R. 2013: Biomod2: Ensemble Platform for Species Distribution Modeling. R package version 3.2.2. URL: http://CRAN.R-project.org/package=biomod2.

VAN KLINKEN R.D. \& HEARD T.A. 2000: Estimating fundamental host range: a host-specificity study of a potential biocontrol agent for Prosopis species (Leguminosae). - Biocontr. Sci. Techn. 10: 331-342.

VAN KLINKEN R.D. \& EDWARDS O.R. 2002: Is host-specificity of weed biological control agents likely to evolve rapidly following establishment? - Ecol. Lett. 5: 590-596.

van KlinKen R.D. \& RaghU S. 2006: A scientific approach to agent selection. - Aust. J. Entomol. 45: 253-258.

van Proosdij A.S.J., Sosef M.S.M., Wieringa J.J. \& Raes N. 2016: Minimum required number of specimen records to develop accurate species distribution models. - Ecography 39: $542-552$.

van Wilgen B.W., Moran V.C. \& Hoffmann J.H. 2013: Some perspectives on the risks and benefits of biological control of invasive alien plants in the management of natural ecosystems. - Environ. Manag. 52: 531-540.

Villemant C., Barbet-Massin M., Perrard A., Muller F., GarGOMINY O., Jiguet F. \& Rome Q. 2011: Predicting the invasion risk by the alien bee-hawking Yellow-legged hornet Vespa velutina nigrithorax across Europe and other continents with niche models. - Biol. Conserv. 144: 2142-2150.

WAPSHERE A.J. 1974: A strategy for evaluating the safety of organisms for biological weed control. - Ann. Appl. Biol. 77: 201-211.
WatanABE M. \& HiRaI Y. 2004: Host-use pattern of the ragweed beetle Ophraella communa LeSage (Coleoptera: Chrysomelidae) for overwintering and reproduction in Tsukuba. - Appl. Entomol. Zool. 39: 249-254.

Winston R.L., Schwarzländer M., Hinz H.L., Day M.D., Cock M.J.W. \& Julien M.H. 2014: Biological Control of Weeds: A World Catalogue of Agents and their Target Weeds. 5 ed. USDA Forest Service, Forest Health Technology Enterprise Team, Morgantown, West Virginia, $838 \mathrm{pp}$.

YAMAZAKI K., IMAi C. \& Natuhara Y. 2000: Rapid population growth and food-plant exploitation pattern in an exotic leaf beetle, Ophraella communa LeSage (Coleoptera: Chrysomelidae), in western Japan. - Appl. Entomol. Zool. 35: 215-223.

Zheng X.W., Zhou Z.S., Guo J.Y., WAN F.H., Chen H.S. \& WANG J.G. 2011: Effect of initial densities on population expansion of Ophraella communa. - J. Environ. Entomol. 33: 128-130.

Zhou Z.S., Chen H.S., Guo J.Y., Guo W., Luo Y.H., Zheng X.W., Luo M., ZHENG H.Y. \& WAN F.H. 2011a: A field trial of biological control of Ambrosia artemisiifolia with two herbivorous insects in Miluo, Hunan Province, China. - J. Biosaf. 20: $186-191$.

Zhou Z.S., Chen H.S., Zheng X.W., Guo J.Y. \& WAN F.H. 2011b; Combined control of common ragweed, Ambrosia artemisiifolia with Ophraella communa and Epiblema strenuana in Laibin, Guangxi Province, China. - J. Biosaf. 20: 267-269.

Zhou Z.S., Guo J.Y., Zheng X.W., Luo M., Chen H.S. \& WAN F.H. 2011c: Re-evaluation of biosecurity of Ophraella communa against sunflower (Helianthus annuus). - Biocontr. Sci. Techn. 21: 1147-1160.

Zhou Z.-S., Rasmann S., Li M., Guo J.-Y., Chen H.-S. \& Wan F.-H. 2013: Cold temperatures increase cold hardiness in the next generation Ophraella communa beetles. - PLOS ONE 8(9): e74760, 12 pp.

Zhou Z.S., Chen H.S., Zheng X.W., Guo J.Y., Guo W., Li M., Luo M. \& WAN F.H. 2014: Control of the invasive weed Ambrosia artemisiifolia with Ophraella communa and Epiblema strenuana. - Biocontr. Sci. Techn. 24: 950-964.

Received December 8, 2016; revised and accepted January 30, 2017 Published online March 222017

\section{Supplementary Information 1. Detailed results of the juvenile performance experiment}

Model selection

Table S1. The mixed models in order of their fit to the data on total development time, with egg batch identity as a random variable on the intercept. The "+" indicate fixed factors and interactions included in each model ( $\mathrm{B}$ - species of beetle; $\mathrm{P}$ - species of plant, $\mathrm{C}$ - conditions), $\mathrm{df}$ is the degrees of freedom, AICc is the modified Akaike Criterion Index, $\triangle \mathrm{AICC}$ the difference in $\mathrm{AICc}$ of the best model from those of the set of models, and the evidence ratio indicates the strength of the best model compared to each of the other models, based on the AICc. Model selection (as described in Material and methods) resulted in only one remaining model (above the dotted line), which was the one used.

\begin{tabular}{ccccccccccc}
\hline Model & $\mathrm{B}$ & $\mathrm{P}$ & $\mathrm{C}$ & $\mathrm{B}^{*} \mathrm{C}$ & $\mathrm{P}^{*} \mathrm{C}$ & $\mathrm{df}$ & $\mathrm{AlCc}$ & $\Delta \mathrm{AICc}$ & $\begin{array}{c}\text { Evidence } \\
\text { ratio }\end{array}$ \\
\hline 11 & + & + & + & + & & 7 & 200.6 & 0.0 & \\
full & + & + & + & + & + & 8 & 203.1 & 2.4 & 3.4 \\
10 & + & + & + & & & 6 & 211.9 & 11.2 & 272 \\
12 & + & + & + & & + & 7 & 213.5 & 12.9 & 622 \\
7 & + & & + & + & & 6 & 216.2 & 15.6 & 2405 \\
8 & & + & + & & & 5 & 225.0 & 24.3 & 193165 \\
6 & + & & + & & & 5 & 225.0 & 24.3 & 193610 \\
9 & & + & + & & + & 6 & 226.9 & 26.3 & 515710
\end{tabular}




\begin{tabular}{|c|c|c|c|c|c|c|}
\hline 4 & & + & 4 & 235.4 & 34.8 & $36^{*} 10^{6}$ \\
\hline 1 & & & 3 & 301.4 & 100.7 & $75^{*} 10^{20}$ \\
\hline 2 & + & & 4 & 301.8 & 101.1 & $92^{*} 10^{20}$ \\
\hline 3 & & + & 4 & 303.9 & 103.2 & $261 * 10^{20}$ \\
\hline 5 & + & + & 5 & 304.3 & 103.7 & $323^{*} 10^{20}$ \\
\hline
\end{tabular}

\section{Development time per stage}

Table S2. Pearson correlation coefficient between the development time of each of the larval stages L1-L3, the pupal stage and total time spent developing (from L 1 to adult), for the 38 adults that emerged.

\begin{tabular}{lcccc}
\hline & L2 & L3 & Pupa & Total \\
\hline L1 & 0.321 & 0.580 & 0.482 & 0.734 \\
L2 & & 0.489 & 0.461 & 0.687 \\
L3 & & & 0.568 & 0.822 \\
P & & & & 0.866 \\
\hline
\end{tabular}
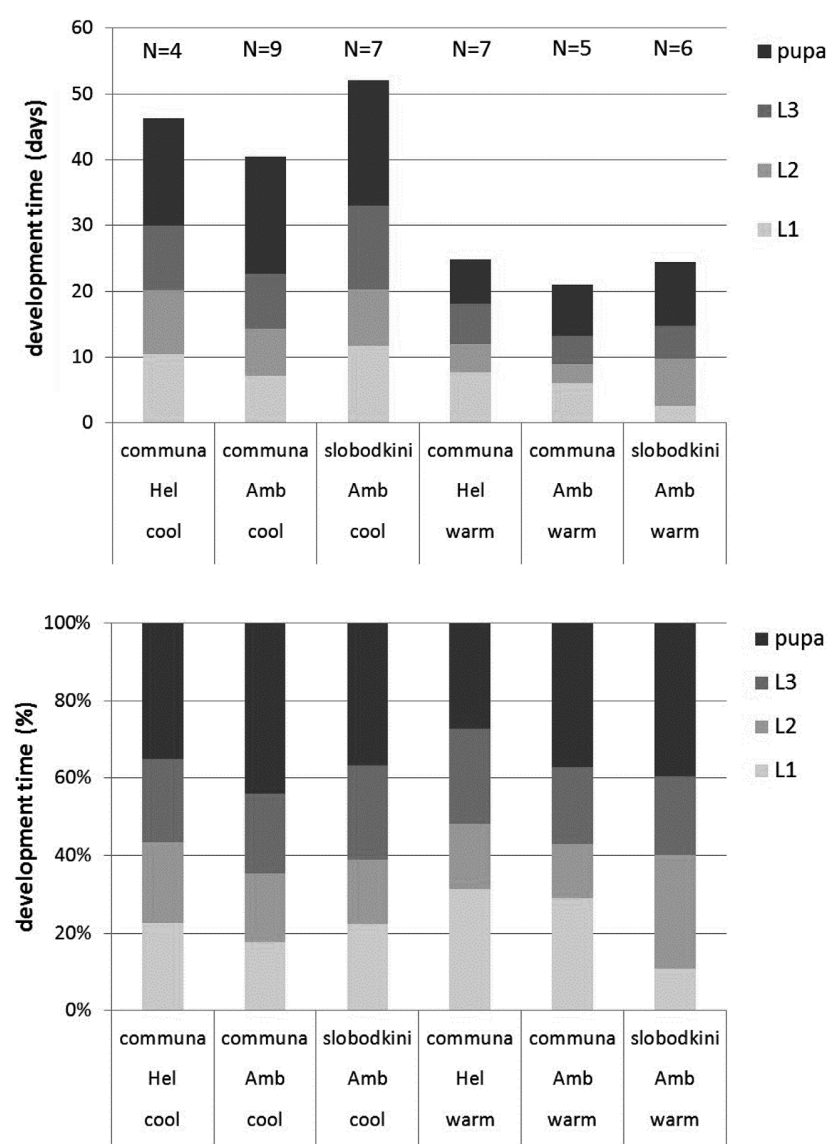

Fig. S1. Mean number of days (above) and corresponding percentage of development time (below) per stage (L1-L3 represent larval stages 1-3) of the two ragweed leaf beetles, Ophraella communa and $O$. slobodkini, reared on ragweed (Amb) and sunflower (Hel) under two different climatic regimes (cool: 14L: 10D at $20 / 12 \pm 1.5^{\circ} \mathrm{C}$; warm: $16 \mathrm{~L}: 8 \mathrm{D}$ at $26 / 18 \pm 1.5^{\circ} \mathrm{C}$ ), for all individuals that developed into adults (numbers per group indicated above bars in upper graph).

\section{Supplementary Information 2. Details of species distribution modeling}

\section{Collection of occurrence data}

We used the following online-resources to obtain geo-referenced occurrence records of the three species Ambrosia artemisiifolia, Ophraella communa and O. slobodkini: GBIF (http:// www.gbif.org), the Southwest Environmental Information Network (SEINet; http://swbiodiversity.org), the Barcode of Life Data Systems (BOLD; http://www.boldsystems.org/), and the Berkeley Ecoinformatics Engine (Ecoengine; https://ecoengine. berkeley.edu/). Additional occurrences of the plant were obtained from the Jepson Herbarium (University of California, Berkeley), the Marion Ownbey Herbarium (Washington State University), the USF Herbarium (University of South Florida), the C.V. Starr Virtual Herbarium (New York Botanical Garden) and J.F. Bell Museum of Natural History Herbarium (University of Minnesota). Additional occurrences of the beetles were obtained from the Essig Museum of Entomology (University of California, Berkeley), the Bohart Museum of Entomology (University of California, Davis), the Bugguide (Iowa State University), the Mississippi Entomological Museum (Mississippi State University), the TAMU Insect Collection (TAMUIC, Texas A\&M University), the C.A. Triplehorn Insect Collection (Ohio State University), the E.H. Strickland Entomological Museum (University of Alberta), the Property and Environment Research Center (PERC, Montana), the Illinois Natural History Survey (INHS; Prairie Research Institute), Florida State Collection of Arthropods (Florida Department of Agriculture and Consumer Services) and McGuire Center collection (MGCL). An additional 11 occurrences of $O$. slobodkini, and 190 of O. communa, were collected from 9 and 55 publications in google scholar by using "Ophraella slobodkini" or "Ophraella communa" as the exact searching phrase, respectively. Finally, data were supplemented with field sample collections. Field surveys in Florida in May-June 2014 yielded 10 occurrences of $O$. slobodkini. For $O$. communa, 227 occurrences were obtained from a field survey in 2013-2014 in Europe through the EU-COST Action on "Sustainable management of Ambrosia artemisiifolia in Europe" (SMARTER); 381 in the USA through personal contact with Prof. Douglas J. Futuyma; and 45 in China with Dr. Zhongshi Zhou.

\section{Selection of climatic variables}

Table S3. The selected bioclimatic variables used in our climatic suitability models for $A$. artemisiifolia, O. communa and $O$. slobodkini (see material and methods for details). Variable numbers refer to the WORLDCLIM bioclimatic variables (http://www.worldclim. org/bioclim), GDD - growing degree days.

\begin{tabular}{ll}
\hline Species & Climate variables $^{\mathrm{a}}$ \\
\hline A. artemisiifolia & $1,3,4,5,6,7,9,14, \mathrm{GDD}$ \\
O. communa & $5,7,9,11,13,16,17,19$, GDD \\
O. slobodkini & 6,17, GDD \\
\hline
\end{tabular}

a1 - Annual Mean Temperature; 2 - Mean Diurnal Range [Mean of monthly (max temp - min temp)]; 3 - Isothermality (2/7) (*100); 4 - Temperature Seasonality (standard deviation *100); 5 - Max Temperature of Warmest Month; 6 - Min Temperature of Coldest Month; 7 - Temperature Annual Range (5-6); 9 - Mean Temperature of Driest Quarter; 11 - Mean Temperature of Coldest Quarter; 13 - Precipitation in Wettest Month; 14 - Precipitation in Driest Month; 16 - Precipitation in Wettest Quarter; 17 - Precipitation in Driest Quarter; 18 - Precipitation in Warmest Quarter; 19 - Precipitation in Coldest Quarter. 